\title{
BANHO DE REALIDADE
}

\section{Projeto da FGV-EAESP mergulha alunos de graduação no estudo in loco de projetos sociais em todo o país, ampliando horizontes e habilidades de estudantes}

\footnotetext{
Numa época em que a sociedade mostra preocupações crescentes com temas ligados à responsabilidade social, jovens profissionais são solicitados a dialogar e buscar soluções para realidades muito distantes das suas.

Mas quem interagiu a vida toda quase que apenas com seus iguais costuma ter dificuldade para entabular esse diálogo, por mais sólida que seja sua formação. É o que descobrem os alunos que participam do Conexão Local, projeto da FGV-EAESP que se iniciou em 2005 e leva graduandos do $2^{\circ}$ ao $5^{\circ}$ semestre para áreas socialmente vulneráveis do Brasil, com o desafio de desvendarem o funcionamento, os êxitos e os problemas de projetos sociais implementados pelo poder público ou por organizações não governamentais, e ajuda a propor melhoras ou soluções para eles.

O objetivo do programa é estimular o interesse e o envolvimento dos estudantes em experiências inovadoras de gestão social e de desenvolvimento econômico local, com enfoque em políticas públicas, combate à pobreza e promoção da cidadania.

Os alunos selecionados são divididos em duplas e designados para um projeto, segundo a área de interesse. Depois de uma rápida preparação, eles submergem durante três semanas na pesquisa de campo, na primeira delas acompanhados por um supervisor, que é um estudante de mestrado ou doutorado, também da EAESP. Na volta, escrevem um relatório, analisando o projeto estudado e seus impactos. Em 2008, o projeto deixou de ser restrito a alunos da Escola ao ter a primeira dupla mista, formada por um aluno da Escola e outro da Universidade Federal do Acre, prática que se tornou habitual a partir do ano seguinte, com a participação de diversas universidades.
} 


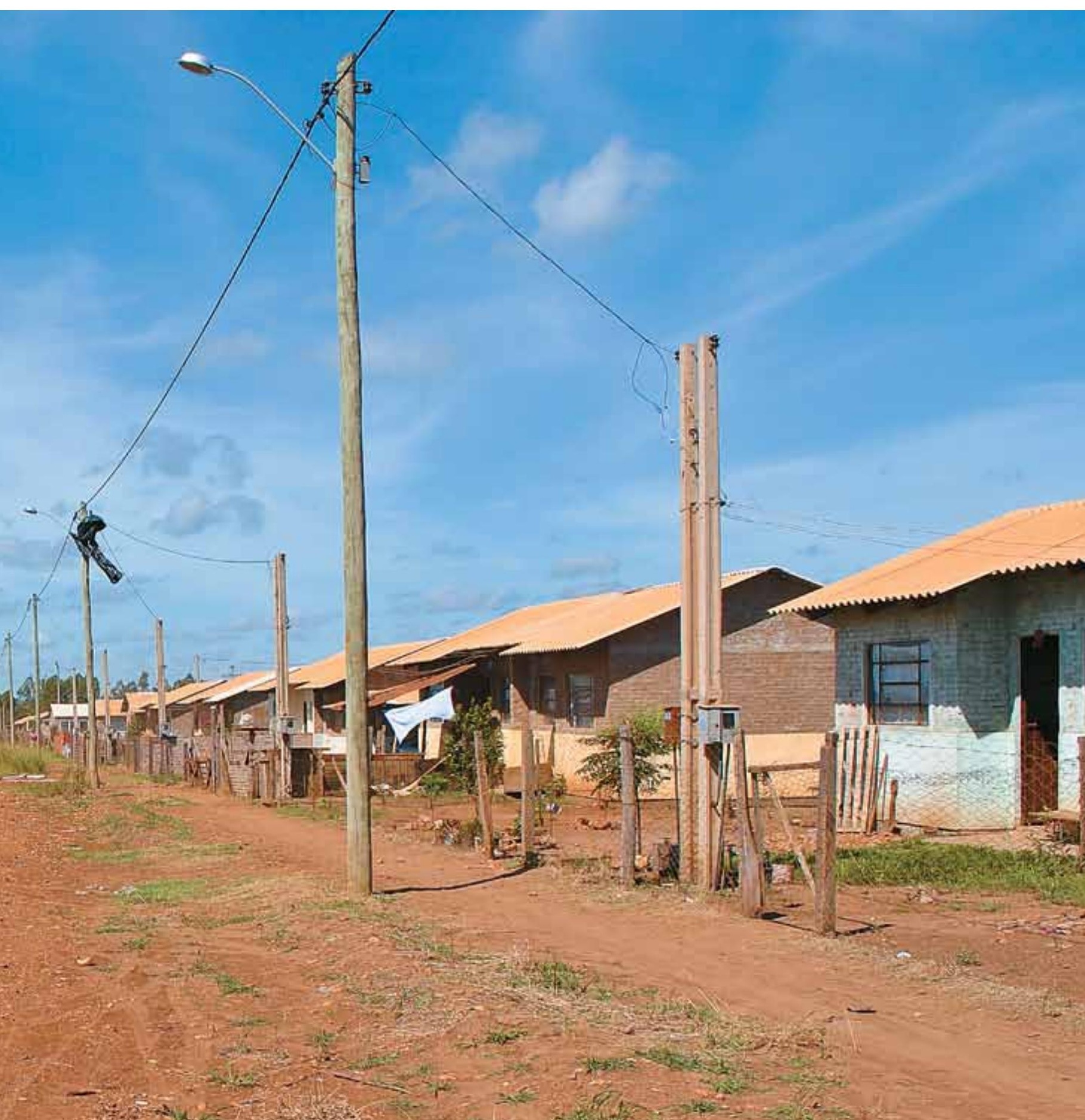

(2. $9: 2$

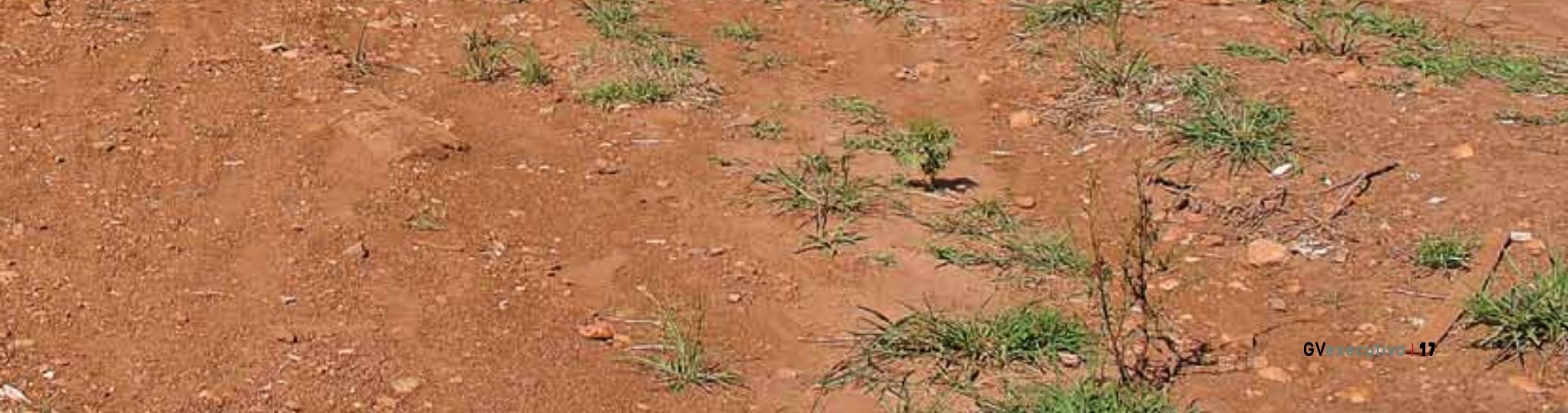


"Minha cabeça mudou radicalmente, voltei com mais facilidade para entender e criticar conceitos e pressupostos de macro e microeconomia. O que era abstrato ganhou referência no mundo real", conta Cesar Matsumoto, aluno de Administração Pública que passou um mês no Conjunto Palmeiras, comunidade carente na periferia de Fortaleza, estudando o funcionamento do Banco Palmas - que tem um programa de inclusão financeira para os moradores do bairro.

Paulistano de classe média, Matsumoto só tinha estado no Nordeste como turista, hospedado em um bom hotel. "Mergulhar naquela realidade como pesquisador foi um grande crescimento". Ele gostou tanto da experiência que, passadas as três semanas do projeto, decidiu esticar mais uma por conta própria, dedicando seus últimos dias de férias a aplicar seus conhecimentos acadêmicos para aprimorar os serviços da instituição. "Fiz o georreferenciamento da economia local para melhorar a análise de viabilidade de novos empreendimentos que pleiteiam crédito".

A aluna de Administração de Empresas Sabrina Balhes também esteve no Nordeste. Ela e o parceiro Raul Gouvêa visitaram diferentes projetos de geração de emprego e renda em quatro cidades do interior da Paraíba, entre as quais Cacimbas, a de pior IDH daquele estado, e Pombal, primeiro município a ter beneficiários abdicando do Bolsa Família por avaliarem que não precisavam mais da ajuda.

Sabrina garante que a viagem mudou sua visão dos projetos sociais. "Eu só ouvia que no Nordeste as pessoas recusavam trabalho para viver do Bolsa Família, mas vi lugares onde não existia alternativa de trabalho e os $\mathrm{R} \$ 70$ do benefício faziam toda a diferença. Conheci um garoto que largou a escola porque selecionar lixo dava mais dinheiro que a Bolsa... Em Pombal, vi quantos beneficiários do programa estavam se capacitando para conseguir emprego, e conheci uma senhora que usou o benefício para comprar pintos, montar um galinheiro e poder abdicar da Bolsa", conta a estudante.

"Aprendi que antes de opinar sobre realidades distantes da nossa é importante conhecê-las e se colocar na pele de quem as vive. Hoje imagino o tipo de trabalho que alguém pode recusar para não perder os $\mathrm{R} \$ 70$ da Bolsa".

Depois do Conexão Local, Sabrina decidiu fazer um projeto de iniciação científica para analisar até que ponto a transferência de renda do Bolsa Família favorece maior independência da população dos laços de clientelismo com políticos locais.

\section{Os alunos relatam experiências enriquecedoras. Além de conhecerem um outro Brasil, muitos voltam com novas perspectivas para a vida depois de formados}

OUTRO BRASIL. A estudante de Administração Pública Mônica Quintiliano classifica o Conexão Local como "um divisor de águas" em sua vida. "Conheci um Brasil que eu não sabia que existia, com lugares tão pobres que não têm mendigos porque eles não teriam para quem pedir", conta a estudante, que analisou o programa de saúde Trevo de Quatro Folhas, procurando entender como a prefeitura de Sobral, no sertão cearense, havia logrado reduzir a mortalidade infantil para menos da metade com medidas simples e de baixo custo, focadas no atendimento pré e pós-natal das gestantes vulneráveis.

Para conhecer a experiência e avaliar seus impactos, Mônica e seu parceiro acompanharam as visitas às famílias, ouviram os beneficiados, membros da equipe e diretores da Escola de Saúde Pública e da Santa Casa. "Visitar uma casa onde dez pessoas vivem em um cômodo sem luz nem água encanada e ver o impacto das políticas sociais implementadas me deu uma nova perspectiva do trabalho que poderei desenvolver como profissional", avalia Mônica.

Paulistano de classe média alta, Marcelo Yazaki não conhecia quase nada sobre o mundo rural quando percorreu 5 mil quilômetros no interior do Mato Grosso do Sul visitando 
30 municípios para analisar um programa de verticalização da agricultura familiar implementado para aumentar a geração de renda no setor. Ele e seu parceiro no projeto entrevistaram desde agricultores beneficiários finais do programa até os técnicos e políticos que o conceberam, passando por prefeitos, secretários municipais de agricultura e técnicos de órgãos públicos que o implementaram.

"Um programa excelente pode não funcionar quando depende muito do apoio do Estado, e esse apoio não contempla todas as frentes necessárias. Conheci um Brasil que eu não imaginava, e comecei a achar importante ter opinião própria sobre questões como reforma agrária e distribuição de renda. Muitos não entendem por que um aluno da FGV se meteu num projeto como esse, mas para mim foi o melhor projeto que já fiz. Percebi como é importante entender o lado de todo mundo", explica Yazaki.

Embora seja filha de fazendeiro, Sarah Transferretti também avalia que o Conexão Local ampliou sua capacidade de se comunicar e interagir com outras realidades. "Sempre mantive um diálogo superficial e distante com os funcionários da fazenda do meu pai. O projeto mudou isso, me ensinou a falar a linguagem deles, me mostrou como essa gente é aberta e o quanto tem para ensinar", conta a estudante, que passou três semanas visitando o projeto Casa Nossa de Cada Dia, de Sobral, um dos mais antigos projetos sociais focados no combate à mortalidade infantil e materna.

"Eu sabia dos problemas de mortalidade infantil em outros países, mas não tinha noção da precariedade das condições de vida em algumas partes do Brasil", conta a estudante, que chegou a dormir numa das comunidades visitadas. "Ver gente que consegue ser feliz usufruindo de tão pouco me ensinou a pensar mais no outro, o que acho essencial para um bom administrador", avalia Sarah.

SUPERANDO PRECONCEITOS. Os depoimentos ilustram bem como o programa cumpre seus objetivos de trazer um pouco da diversidade do país para os estudantes da EAESP, ao mesmo tempo que os inicia nas técnicas de pesquisa de campo. "Nossos alunos têm excelente formação, mas uma bagagem enviesada: lidam muito bem com o pedaço da realidade que conhecem, mas não têm acesso à diversidade que caracteriza o país. O programa foi concebido para preencher essa lacuna", explica o professor Ricardo Bresler, que coordenou o Conexão Local por alguns anos.

Segundo Bresler, uma das fontes de inspiração foram os intercâmbios internacionais feitos por vários alunos. "Pensamos que, se ir para o exterior era tão enriquecedor, porque não promover também o contato com a diversidade das realidades do país", conta.

Geórgia Carapetkov do Nascimento, que foi supervisora de Sabrina e Raul enquanto cursava o doutorado, avalia que a interação com os alunos foi muito produtiva para sua pesquisa, que analisou o Bolsa Família e outros projetos de geração de renda no sertão da Paraíba. "Com eles, tive dois outros olhares sobre projetos que também eram tema da minha pesquisa. Foi enriquecedor porque somos muito diferentes", conta Geórgia. Já Oswaldo Gonçalves Júnior, supervisor do projeto por dois anos seguidos, acabou de definir seu estudo de doutorado a partir do que viu durante a primeira viagem com os alunos.

Fernando Burgos, supervisor dos alunos do Conexão Local desde 2006, também enriqueceu sua pesquisa sobre desenvolvimento local com as viagens do projeto, embora destaque que esse não é o foco do supervisor. "Ajudar os alunos de graduação a superar preconceitos e assumir o olhar de pesquisador para compreender realidades diferentes da sua é o grande desafio. Para isso, é preciso romper com a visão consensual do Brasil retratada pela mídia", frisa Burgos. Gonçalves concorda e acrescenta: "Observar os alunos de graduação no contexto desses projetos sociais é quase tão interessante como observar os próprios projetos".

SIMONE BIEHLER MATEOS, jornalista,

simonemateos@gmail.com 